\title{
ENVIRONMENTAL ASSESSMENT IN THE BUILDING MATERIALS INDUSTRY: HOW ARE THE RESULTS OF LIFE-CYCLE-ASSESSMENT (LCA) FOR CONCRETE INFLUENCED BY TECHNOLOGY AND REGULATIONS?
}

\author{
Ronny Meglin M.Sc. \\ Prof. Dr. Susanne Kytzia \\ HSR University of applied sciences Rapperswil, Switzerland
}

\begin{abstract}
In the building material industry, sustainability concerns are dominated by the role of raw materials, especially in the production of cement (e.g. fuels) and concrete (e.g. recycled aggregates). As raw materials become increasingly scarce worldwide, this an accelerating challenge faced by both individual companies and countries. To investigate the environmental impact of the building materials industry, a widely accepted tool is the Life Cycle Assessment (LCA). Although LCA is frequently used to evaluate the sustainability of building materials, recent studies show that the interpretation of LCA results can be difficult in sustainable construction due to ambiguity of underlying assumptions.
\end{abstract}

In the ongoing research project "Co-Evolution of Business Strategies in material and construction industries and public policies" we analyse how the results of LCA for concrete building materials are influenced by the production technology, regulations (e.g. waste treatment), socio-technical settings (e.g. energy supply systems) and methodological choices in LCA. Our results are based on an intensive literature review and scenario analysis based on a model of the concrete product system using LCA.

It shows that differing results of LCA studies can be accounted to variations of cement content, clinker to cement ratio or share of alternative fuels in the fuel mix in cement production. Alternative methodological choices in LCA influence the results for Global Warming Potential GWP when carbon uptake during service life and recycling of concrete is considered (shift of perspective from cradle-to-gate to cradle-to-grave). Allocation rules for SCMs (e.g. ground granulated blast furnace slag GBFS) or alternative fuels also have a relevant effect on LCA results for GWP and Cumulative Energy Demand CED.

Keywords: Life cycle assessment, global warming potential, cumulative energy demand. 


\section{INTRODUCTION}

Reducing environmental impacts of concrete is a major challenge in sustainable construction. Habert et al. (2016) analyzed the environmental impact of 37 buildings and identified reinforced concrete as the largest contributor to impacts related to the production of building materials. Cement and concrete producers are under significant pressure worldwide to reduce $\mathrm{CO}_{2}$ emissions and resource consumption (CEMBUREAU The European Cement Association, 2013; CSI, 2018; Habert et al., 2018) because of the high energy and material intensity of their current production processes.

Life Cycle Assessment (LCA) is decision support tool frequently used and well established to promote sustainable management as well as sustainable construction. International standards for LCA have been developed and the database for construction materials is constantly growing (Passer et al. (2015). In many countries, this data is used in building labelling and certification schemes for sustainable construction.

Looking at different LCA studies for concrete there is a surprisingly wide rage in the results for different environmental impacts such as Global Warming Potential (GWP) or Cumulative Energy Demand (CED). Some of this variation can be explained by the use of different data sources or methodological choices (Dossche, Boel and Corte, 2017; Ehrenberg, 2018; Passer et al., 2015). Yet, even within an identical methodological framework using the same data sources, results can vary up to $100 \%$ for the same type of concrete (NRMCA, 2016). For LCA experts, this reveals the need to further develop the method (Abd Rashid and Yusoff, 2015; Augiseau and Barles, 2017; Buyle, Braet and Audenaert, 2013; Petek Gursel et al., 2014; van den Heede and Belie, 2012). It would be already very useful for users of LCA data in sustainable construction and management, to better understand why the results of LCAs for concrete differ so much.

In this paper, we try answer this question by revealing how methodological choices in LCA affect the results of LCA studies of the concrete product system. We further investigate the effect of technological choices in cement and concrete production on the results of LCA studies. Our results are based on a literature review - presented in sections 2 und 3 - as well as scenario analysis based on a model of the concrete product system using LCA (presented in sections 4 und 5).

In the discussion in section 6, we will compare the effects of technological choices on selected environmental impacts in the life cycle of concrete and reveal what methodological choices in LCA help to reveal these impacts. With our findings, we hope to encourage the development of practical guidelines for the interpretation of LCA results of concrete building materials, and advance LCA calculating techniques for this product category.

\section{LCA - METHOD}

Life cycle assessment (LCA) is a methodological framework used to assess environmental impacts of a product or service from a life cycle perspective, including resource extraction, production, use and end-of-life activities (e.g. waste treatment). Its development started in the 1960s focusing on the comparison of environmental impact of consumer goods and first studies in the construction sector appear in 
the1980s (Buyle, Braet and Audenaert, 2013). A common methodological framework wasn't developed until the late 1990s when the International Organization for Standardization (ISO) published its 14040 series (SNV, 2006b, 2006a)

Since then, the interest in LCA rapidly increased. It encouraged the development of a specific methodological framework for LCA of building materials and products with a set of environmental data defined by pre-set categories of parameters based on the ISO14040 series. It results in Environmental Product Declarations (EPDs) and was standardized on a general level by ISO (ISO Technical committee (TC) 59 'Building Construction') (ISO/TC 59/SC 17, 2017) as well as by the European Committee for Standardization (CEN) in its Technical Committee (TC) 350 'Sustainability of construction works' (Schweizerischer Ingenieur- und Architektenverein SIA, 2014). This led to the emergence of EPD programs (mostly in Europe, Canada and the US) that started developing and publishing specific methodological frameworks for product categories, called PCRs (Product Category Rules). In 2015, (Passer et al., 2015) state that more than 28 EPD programs exist worldwide referring to ISO 14025" (...), providing more than 2256 PCR documents and more than 3600 EPDs (see (Passer et al., 2015, p. 1201). Yet, the growing number of LCA studies for construction materials also revealed the need to further develop the method (Abd Rashid and Yusoff, 2015; Augiseau and Barles, 2017; Buyle, Braet and Audenaert, 2013; Petek Gursel et al., 2014; van den Heede and Belie, 2012).

In the following paragraphs we give a brief description of the existing methodological framework and then highlight specific issues in LCA that are relevant for assessing environmental impacts of concrete. We focus on issues related to modelling the process chain in the life cycle of concrete and represented in life cycle inventories (LCIs).

\subsection{Short Description of the Methodological Framework}

A LCA is carried out in the four steps: defining goals and scopes of the study, life cycle inventory (LCI), environmental impact assessment (LCIA) und interpretation. It is intended as an iterative process delivering meaningful and robust information to support decision making in environmental management and sustainable construction. Most LCAs are used to compare products or services providing comparable functions. This definition of functions is a main issue in the first step of defining goals and scopes. This step further includes the determination of the purpose of the study as well as the system boundaries. In the second step, data of relevant inputs and outputs is collected for all processes within the defined system boundary and related to the functional units. This data is used to model the product systems under study.

In the next step, the data provided by the product system models is used to evaluate their potential environmental impacts and resource consumption. This environmental impact assessment (LCIA) connects each LCI result (emission or resource consumption) with one or several corresponding environmental impact categories (e.g. Global Warming). Specific assessment models for each impact category allow evaluating the effect of a product system related to this impact (e.g. Global Warming Potential). As a result, the analysis presents impact value for each product system for a limited number of impact categories. 
Based on the results of LCI and LCIA, significant issues in the product systems are identified in order to reach conclusions with regard to the goal of the study, explain the limitations and provide recommendations. This interpretation is the last step in the LCA. It may include uncertainty as well as scenario analyses.

\subsection{Specific Issues in LCA for Concrete}

In this section, we focus on the first two steps in LCA: definition of goals and scope and Life Cycle Inventory. As pointed up in (Rebitzer et al., 2004), important choices and assumptions are made in the first step (definition of goals and scopes) and it is often decisive for the results of an LCA study. Therefore, choices regarding "functional unit" and "system boundaries" are discussed in the following subsections $a$ und $b$. Based on these choices and assumptions, a model of the product system is developed in the Life Cycle Inventory. It is typically a static and linear simulation model. In the process chain of concrete production, many secondary resources are used to substitute fuels or mineral resources. In theory, this results in circular flows (e.g. after demolition crushed concrete is used to produce new concrete), that cannot be represented in a linear model. Thus, the model builders have to decide for each process how to deal with secondary resources. Are they considered as by-products of the process they originate from or are the considered as wastes to be treated as by-product of cement and concrete production? Such questions are addressed in subsection c.

Impact assessment is not addressed as a specific issue in LCA for concrete as we are not going to analyze this issue in this paper. It could be addressed in further research as LCA studies for concrete have a methodological bias in impact assessment. All studies highlight the importance of concrete and cement production for global warming, whereas impacts on the local environment caused by mining and landfilling - such as changes in landscape, water management, biodiversity etc. are generally neglected due to a lack of suitable assessment models. In consequence, advantages of using recycled aggregates in concrete production are not fully represented in LCA studies.

\section{a) Functional Unit}

If an LCA is used to compare alternative options in decision-making, the functional unit and the corresponding reference flow are the most important parameters defined in the first step. The functional unit describes the services provided by the product system under study.

In LCAs for concrete, the definition of functional units is a challenge because concrete can be used for many different purposes. (van den Heede and Belie, 2012) point out that LCA of concrete can vary significantly from the material level (i) onto the structure level (ii). On material level, the functional unit is usually defined as one cubic meter of concrete with equivalent mechanical performance and durability. However, on the structural level structural elements have to be defined (e.g. column, beam, slab) with given mechanical load and a predefined service life. In addition to the concrete needed to produce these structural elements, the steel for reinforcement has to be considered. 
Yet, most LCA studies for concrete define the functional unit on material level and the reference flow is given by alternative mix designs (e.g. (NRMCA, 2016)). The definition of types of concrete with equivalent mechanical performance is mostly given by product standards that can also include a characterization of classes of exposure (van den Heede and Belie, 2012, p. 435).

\section{b) System Boundary}

In principle, an LCA should cover the entire product life cycle starting with resource extraction (from the environment) and ending with the final disposal of wastes (to the environment) at the end of a products service life. In an LCA, all processes necessary to produce the product or service (upstream processes) are assumed to be fully elastic implying a linear relationship between the reference flow - representing the functional unit - and both the amount of resources consumed and the amount of emissions produced. From the producers' perspective, all processes related to the use-phase (operation, maintenance, repair and overhaul) and the end-of-life-phase (demolition, recycling, waste treatment) are called downstream processes. In LCAs for durable goods, modelling downstream processes has to deal with uncertainties with regard to service life, user behavior, maintenance strategies and future waste management technologies. The methodological framework of EPDs suggests scenario analysis to deal with such uncertainties. However, many LCAs for building products limit the analysis to upstream processes. This choice of system boundaries is often referred to as "cradle to gate" in contrast to the originally intended "cradle to grave".

Since the discussion of $\mathrm{CO}_{2}$ sequestration during service life and demolition of concrete started, some LCAs for concrete extended the system boundaries to downstream processes (Butera, Christensen and Astrup, 2015). Carbon uptake during the use phase largely depends on how long the concrete surface of a structural element is exposed to air. This effect can only be included in a meaningful way when the functional unit is defined on a structural level. Carbon uptake of demolished concrete can also be assessed with a functional unit on a material level because the surface and the time of exposure of crushed concrete can be defined by the processes of demolition and waste treatment independent of the former use of the structure. This effect is taken into account in more recent LCAs for concrete (e.g (InformationsZentrum Beton $\mathrm{GmbH}, 2018)$ ).

\section{c) Allocation Rules}

The model of the product system developed in the second step, the so-called Life Cycle Inventory, is composed of unit processes, which each represent inputs of natural resources, the emissions, waste flows, and other environmental exchanges related to an intermediate product flows (e.g. electricity needed to produce a good or service). When a unit process provides more than one product or service, allocation rules are needed to distribute the inputs, emissions etc. among the multiple products and services. According (Rebitzer et al., 2004) and (Chen et al., 2010), the definition of such allocation rules is one of the most controversial topics within the LCA community. The ISO standards suggest a procedure in three consecutive steps (SNV, 
2006a). The first step is to expand the system studied "to include the additional functions related to the co-products". If no such system expansion is feasible, it suggests to separate the exchanges "in a way which reflects the underlying physical relationships between them, i.e., they shall reflect the way in which the inputs and outputs are changed by quantitative changes in the products or functions delivered by the system." When both options fail, the ISO procedure suggests distributing the exchanges with the environment and upstream processes "between the products and functions in a way which reflects other relationships between them. For example, input and output data might be allocated between coproducts in proportion to the economic value of the products." The last option is still the most commonly applied although it has the lowest priority in the ISO series (Finnveden et al., 2009, p. 9).

LCAs for concrete include a number of multi-output-processes because a lot of secondary material is used in production: alternative fuels and resources (AFRs) in the cement ciln (furnace), supplementary cementitious materials (SCM) in cement or concrete production and crushed concrete in concrete production using recycled aggregates. Each of these processes provide a good (clinker, cement and concrete) as well as a waste management service (waste incineration, waste treatment and recycling). LCA studies for concrete suggest a wide variety of solutions to this problem.

\section{Allocation of Emissions Associated with the Use of AF in the Cement Ciln}

Alternative fuels used in a cement ciln are generally considered as waste. All LCA studies known to the authors treat them as "burden free", implying that all impacts of the former life cycle of these goods (tires, oil, plastic packaging etc.) are neglected as well as the impacts of transport of these wastes to cement production. Yet, there a different ways of modelling emissions caused by burning alternative fuels in a cement ciln. Most LCA studies model them in compliance with " $\mathrm{CO}_{2}$ Emissions Monitoring and Reporting Protocol for Cement Industry", prepared by Working Group Cement of World Business Council for Sustainable Development (Cementos Argos Panamá, 2014). It includes $\mathrm{CO}_{2}$ Emissions caused by burning alternative wastes from products based on oil (e.g. waste tires, waste oil, plastic waste) whereas alternative wastes from products based in biomass are not considered (e.g. waste wood, dried sewage sludge). Some LCA studies don't consider any emissions caused by burning alternative fuels in the cement ciln because they are regarded as part of the waste treatment processes in the former life cycle of these goods (e.g. (CemSuisse, 2016) (InformationsZentrum Beton $\mathrm{GmbH}, 2018)$ )

\section{Allocation of Impacts Associated with the Use of Scms in Cement and Concrete} Blast furnace slag and fly ash are most frequently used as SCMs and are considered as by-products of steel and electricity production by the European waste regulation. Therefore, a share of the impacts from steel or electricity production is attributed to blast furnace slag and fly ash. Some LCA studies only consider impacts for processing these by-products and transportation to cement production (e.g. (Tait and Cheung, 2016, p. 854)) whereas others consider them as "burden free" inputs (van den Heede and Belie, 2012, p. 438). (Chen et al., 2010) and (Ehrenberg, 2018) discuss the effects 
of alternative allocation rules including economic and physical allocation. (Habert, 2013) suggests a new allocation procedure based on opportunity costs in cement, steels and electricity production generated within the European Union Greenhouse Gas Emission Trading System.

\section{CONCRETE PRODUCTION}

Along the value chain of cement and concrete production several strategies have been identified to reduce environmental impacts (CEMBUREAU The European Cement Association, 2013; CSI, 2018; Habert et al., 2018; Preston and Lehne, 2018; Salas et al., 2016). Most effective strategies are:

- improving the energy efficiency of cement plants and substituting fossil fuels in the cement ciln

- reducing the clinker content in cement (clinker to cement ratio)

- reducing the cement content in concrete

- optimizing the use of concrete in construction

(Habert et al., 2018) claims, that $\mathrm{CO}_{2}$-emissions of concrete production worldwide could be reduced by about $80 \%$ until 2050 if all strategies were implemented in parallel by different stakeholders.

In the following paragraphs, we give a brief description of the current state of technology regarding the implementation of these strategies and analyze implications on emissions and resources consumption in cement and concrete production in different countries.

\subsection{Energy Efficiency}

Due to continuous technological innovations and upgrading of old plants, energy efficiency of the clinker production improved steadily in the last decades. In average around 3.3 GJ are needed to produce one ton of clinker in Europe. By using the best available technology (BAT) the efficiency can be increased to around 2.9-3.0 GJ/to clinker (Preston and Lehne, 2018). The IEA states (CSI, 2018) that by 2050 the energy efficiency can be further increased by $10 \%$.

\subsection{Substitution of Fossil Fuels}

As stated before, the cement industry is energy intensive with high $\mathrm{CO}_{2}$ - emissions (Aranda Usón et al., 2013; Supino et al., 2016). Approximately $40 \%$ of the emitted $\mathrm{CO}_{2}$ are caused by burning fossil fuels in the cement ciln. Therefore, a substitution of fossil with alternative fuels - such as waste wood, waste tires, waste oil etc. - leads to a significant reduction of $\mathrm{CO}_{2}$ emissions. In Europe, in average, over $40 \%$ of the fuel consumption consists of alternative fuels (Preston and Lehne, 2018). In 2017, Switzerland in fact substituted around $63 \%$ of fossil fuels with alternative fuels (CemSuisse, 2018). Hence, the $\mathrm{CO}_{2}$ emissions caused by primary fossil fuels decreased by over $60 \%$ from 1.3 Mio tons of $\mathrm{CO}_{2}$ in 1990 to appr. 0.4 Mio. tonnes in 2017 (CemSuisse, 2018). The usage of alternative fuels highly depends on the country 
and their availability. Aranda Usón et al. (2013) show that in Europe the substation ratio in Europe range from $5 \%$ in Spain to $60 \%$ in the Netherlands in 2011.

\subsection{Clinker to Cement Ratio}

Clinker is the main constituent of cement. Its chemical reaction with water results in a strength development and leads to hardened concrete. In order to obtain the required raw materials for clinker both limestone and marl must be calcinated. This calcination process leads to significant $\mathrm{CO}_{2}$-emissions (Aranda Usón et al., 2013).

In ordinary Portland cement (OPC), the clinker to cement ratio is around 95\% (Schweizerischer Ingenieur- und Architektenverein SIA, 2011). In other cement types, the clinker to cement ration can vary from 5 to $95 \%$, where supplementary cementitious materials (SCMs), like fly ash, blast furnace slag or silicate fume, substitute the clinker to obtain particular properties of the hardened concrete. This can also lead to undesired material characteristics and properties, e.g. reducing the speed of the strength development (Schneider et al., 2011). Due to their origin as industrial wastes, SCMs drastically reduce energy demand and $\mathrm{CO}_{2}$ emissions in cement production (Habert et al., 2018). Over the last years, the world-average clinker to cement ratio has been continuously reduced from approximately $82 \%$ in 1990 to 73 $\%$ in 2015. There are significant differences between the clinker to cement ration of countries around the world depending on regulations and regional availability of SCMs (Preston and Lehne, 2018). It is highest in North America with over 80\% and lowest in Brazil with under $65 \%$.

\subsection{Cement Content and Concrete Mix Design}

Optimizing concrete mix designs is another option to reduce the $\mathrm{CO}_{2}$-emissions along the value chain of concrete (Suhendro, 2014) by minimizing the cement content. The European standard EN 206 (Schweizerischer Ingenieur- und Architektenverein SIA, 2016) limits the minimal cement content for concretes with different exposure classes. The national annexes of EN 206 show that minimal cement content varies between different European countries due to different experience with concrete, climatic conditions and raw material availability. It is lowest in Denmark with $150 \mathrm{~kg} / \mathrm{m}^{3}$ and highest in Italy with $320 \mathrm{~kg} / \mathrm{m}^{3}$. Yet, a direct comparison can be misleading as there might be restrictions concerning the cement typ. In Switzerland, for example, for an ordinary concrete used in structural engineering, the cement content is set to be at least $300 \mathrm{~kg}$ (NPK C), no matter, whether the cement is OPC or Portland composite cement. In Denmark, the minimal cement content refers to a small selection of cement types only with emphasis on OPC. Thus, standards can be a barrier to realize sustainable concrete (Suhendro, 2014). In addition, there are some trade-offs to be considered. First, between cement content and clinker to cement ratio. If the minimal cement content is defined for OPC, concrete producers can optimize their concrete mix designs by adding SCMs. In North America, for example, this leads to a high clinker to cement ration on average (see 3.3) whereas concrete mix designs with SCMs are common practice (NRMCA-EPD. Second, a high cement content can help to optimize structural design and, thus, significantly reduce the amount of concrete needed, as shown for Ultra high performance concrete (UHPC) in (Liew, Sojobi and Zhang, 2017; Müller, Haist and Vogel, 2014). 


\subsection{Carbon Uptake}

Concrete is able to capture $\mathrm{CO}_{2}$ in its service life through carbonation. In this process $\mathrm{CO}_{2}$ from air reacts with calcium hydroxide $\mathrm{Ca}(\mathrm{OH})_{2}$ in concrete to calcium carbonate $\mathrm{CaCO}_{3}$. This $\mathrm{CO}_{2}$-binding leads to a significant decrease of the total $\mathrm{CO}_{2}$ emissions in the value chain of concrete (Butera, Christensen and Astrup, 2015; Leemann, Hunkeler and Widmer, 2018). Recent studies show, that concrete can bind up to $24 \%$ of the $\mathrm{CO}_{2}$-Emmissions of clinker production in its service life (Leemann and Hunkeler, 2016). It is assumed that crushed construction and demolition waste (C\&DW) can bind even more $\mathrm{CO}_{2}$ and, therefore, contributes to further reduce $\mathrm{CO}_{2}$ emissions if prepared and stored in a favorable way.

\section{LCAS OF CONCRETE PRODUCT SYSTEMS}

We use an LCA to evaluate how environmental impacts of the concrete product system are affected by (i) variations of technical parameters - as described in section 3 - and (ii) alternative methodological choices in LCA - as described in section 2 . These variations are defined as scenarios in 4.2.

\section{a) System Definition}

The concrete product system under study is show in Figure 1 We analyze the system with two alternative system boundaries.

System boundary A "cradle to gate" includes

- Cement production with kiln and mill with all corresponding up-stream processes needed to supply raw materials (lime stone, clay etc.), fuels (coal, oil etc.) and electricity. The supply of alternative fuels is also included, but the allocation of the associated environmental impacts is defined in different scenarios (see 4.2).

- Concrete production with all corresponding upstream processes needed to supply raw materials (gravel, limestone etc.) and electricity. The supply of SCMs is included, but the allocation of the associated environmental impacts is defined in different scenarios (see 4.2).

- Transport processes between cement and concrete production are explicitly included. All other transport processes are modelled as part of the upstream processes of supplied materials and energy. 


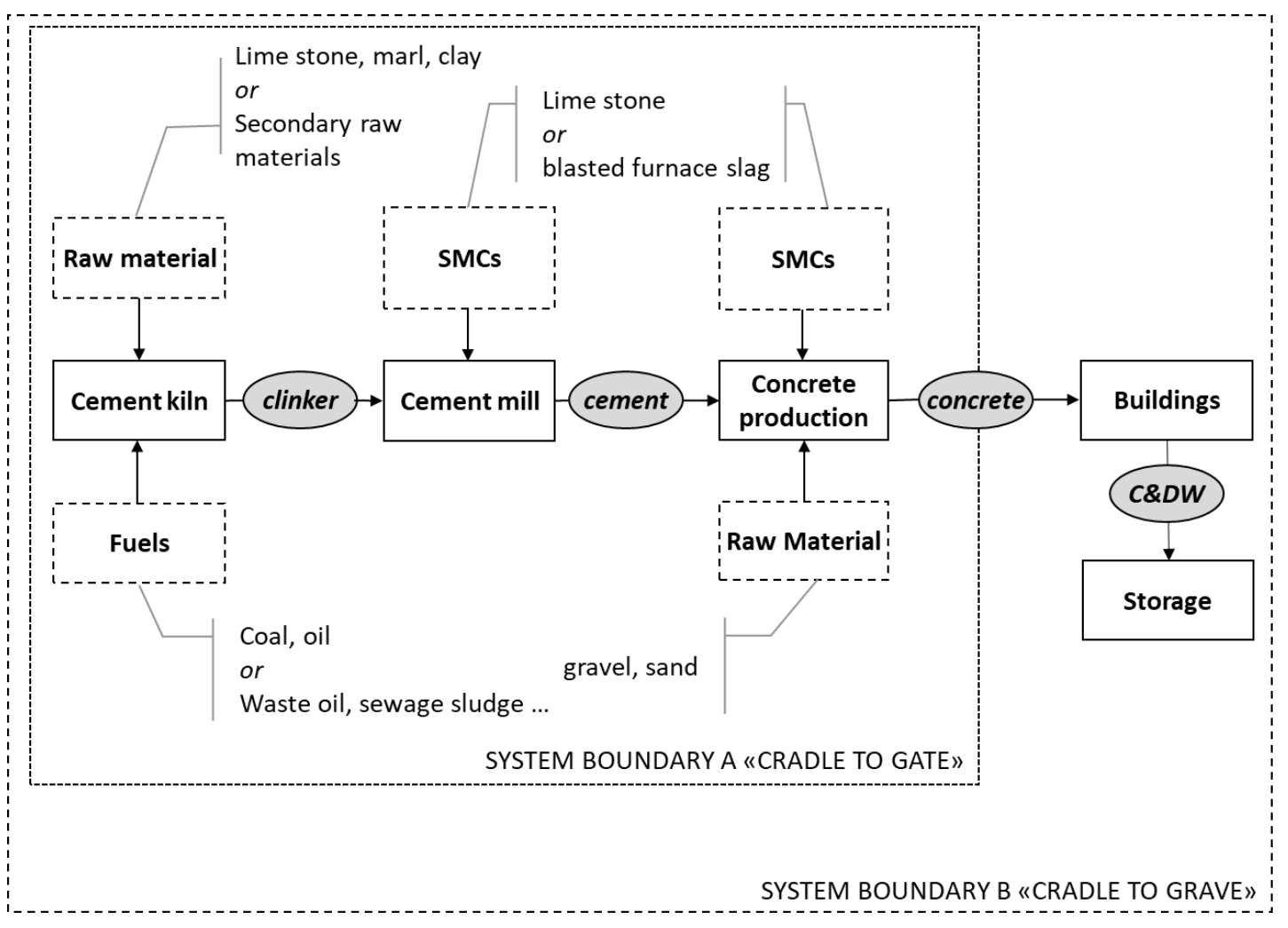

Figure 1: Concrete product system under study

System boundary B "Cradle to grave" includes the system defined as "cradle to gate" as well as the use of concrete during the service life of a structure and storage of crushed concrete at a recycling plant or landfill. We model these processes only to analyze carbon uptake (see 3.6) in a scenario defined in 4.2. No environmental impacts are analyzed for these processes.

\section{b) Functional Unit}

We compare environmental impacts of one cubic meter of concrete of a ordinary construction concrete in Switzerland.

\section{c) Impact Assessment}

We focus on three impact models commonly used in LCA:

- Global warming potential (GWP) according IPCC 2011, 100 years in $\mathrm{kg} \mathrm{CO}_{2-}$ eq.

- Cumulative energy demand (CED) and

- Ecological scarcity 2013 according (Frischknecht, Büsser and Knöpfel, 2013)

While the GWP and CED are generally valid indicators used worldwide, the ecological scarcity is an indicator, developed and implemented in Switzerland (Frischknecht, Büsser and Knöpfel, 2013). Within the framework of this method, the ecological effects are weighted according to the ecological objectives of the respective country. 
The resulting impacts are summarized to create an indicator that can be compared to other products and processes.

\section{d) Data Sources}

The life cycle inventory was set up in SimaPro 8.5 according Section 4.1 The data basis for the LCI is ecoinvent Version 3.4 from November 2017. As basis, the process "Concrete, sole plate and foundation $\{\mathrm{CH}\} \mid$ concrete production, for civil engineering, with cement CEM II/A | Cut-off, $U^{\prime \prime}$ in its version 3.0.2.0 was used and modified in order to enable varying the concrete mix design. The electricity represents the swiss electricity production mix in 2014 . The processes are as follows:

Table 1: Detailed processes for LCA

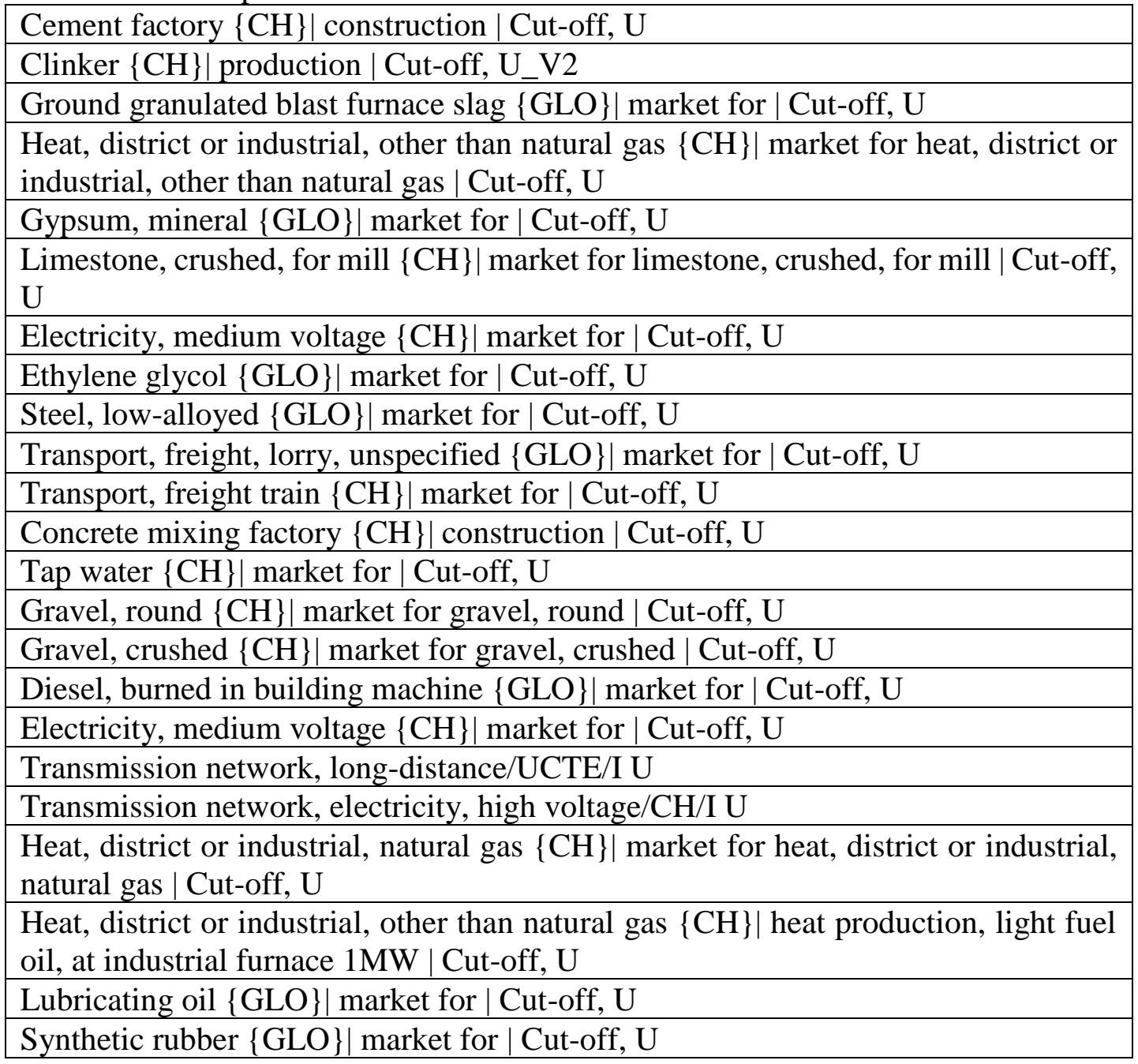




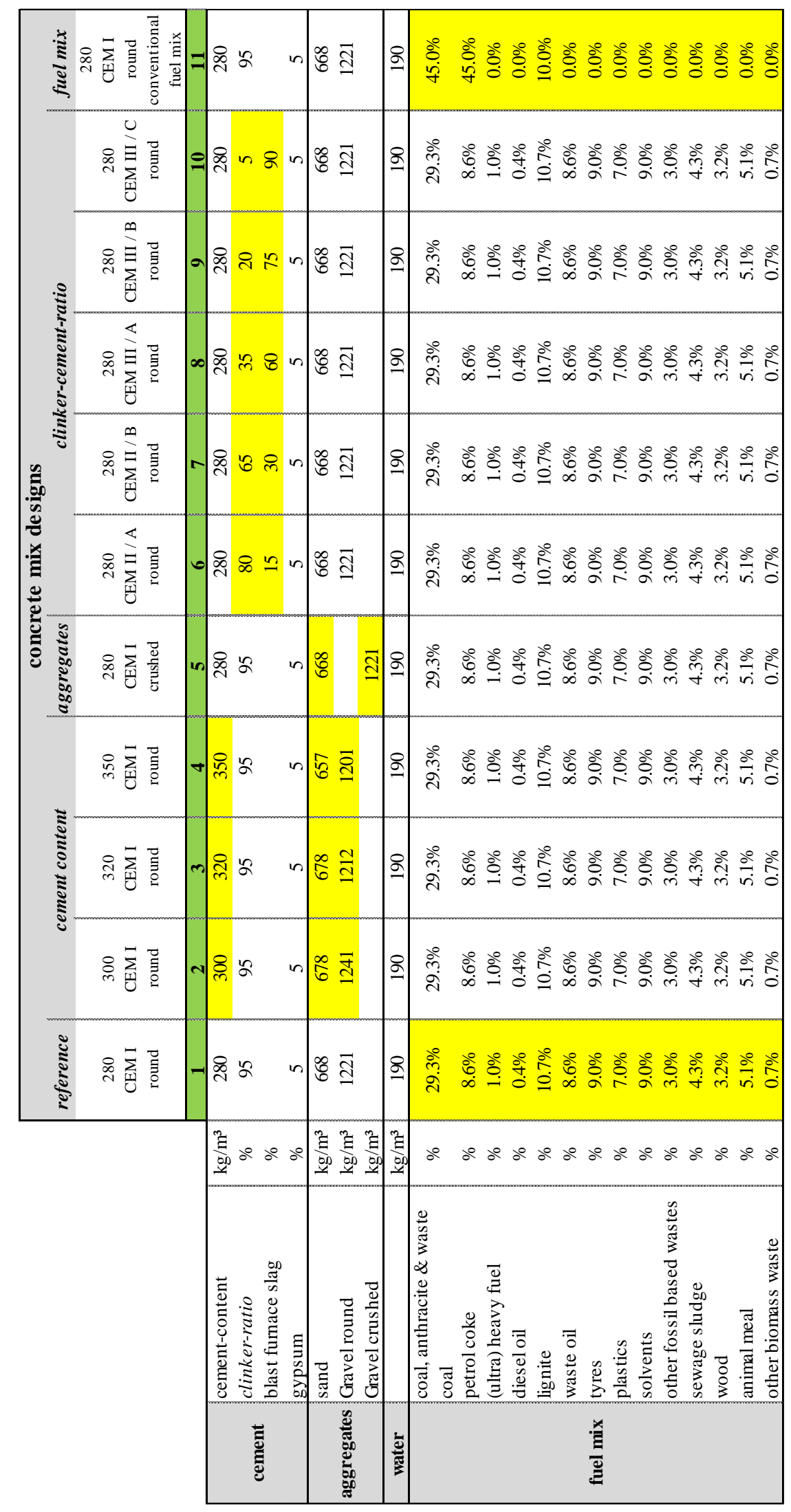

Figure 2: concrete mix designs 


\subsection{Scenario Definition}

Different scenarios are defined (Figure 2) to analyze how environmental impacts are affected by variations of technical parameters and alternative methodological choices in LCA.

We focus on the technical parameters with a significant influence on environmental impacts of the product system (Habert, G. et al. (2018)): cement content level, clinkercement-ratio, geometric shape of the aggregates (round vs. crushed) and substitution rate of alternative fuels in the cement kiln. Energy efficiency is not further considered. Carbon uptake is not considered as technical parameter because no technologies have been implemented up to now to increase $\mathrm{CO}_{2}$ binding during service life and recycling.

An ordinary construction concrete with $280 \mathrm{~kg} / \mathrm{m}^{3}$ and round aggregates was chosen as reference. Then, different cement contents where set, to evaluate the impact of variations of the minimum cement content. Round and crushed aggregates are compared for the reference concrete. Finally, the clinker-cement-ratio is varied by the content of ground granulated blast furnace slag (GGFS) according EN 197 (Schweizerischer Ingenieur- und Architektenverein SIA, 2011) to map the different types of cement and identify the environmental impact of SCMs to the concrete. In the reference scenario, cement is produced based on an average fuel mix for the Swiss cement industry.

The following methodological choices are considered:

- Allocation methods regarding ground granulated furnace slag (GGFS) and alternative fuels (AF),

- System boundary considering carbon uptake (System boundary "cradle to grave" according to Figure 1.

\section{a. Allocation of GGFS}

In the references scenario, the environmental impact of production of ground granulated blast furnace slag is set to be zero meaning that this by-product of the steelindustry comes "burden-free" into the concrete product system. (Chen et al., 2010) propose alternative allocation methods for GGFS based on either mass produced or market prices. Assuming a production of $0.24 \mathrm{~kg}$ GGFS per $\mathrm{kg}$ of steel and market prices of $400 € / t$ (steel) and $40 € / t$ (GGFS), the following allocation coefficients were calculated:

- Mass allocation: $19.4 \%$

- Economic allocation: $2.3 \%$

GWP and CED of $1 \mathrm{~kg}$-eq. (1.11 kg) per kg blast furnace slag allocated with the allocation coeffients by (Chen et al., 2010) are shown in the following Table 2. 
Table 2: Allocation coefficients according (Chen et al., 2010)

\begin{tabular}{|l|l|l|}
\hline & \multicolumn{1}{|c|}{ Mass allocation } & \multicolumn{1}{c|}{ Economic allocation } \\
\hline GWP [kg CO2-eq.] & 1.39 & 0.149 \\
\hline Energy demand [MJ] & 22.2 & 3.54 \\
\hline
\end{tabular}

In our scenario calculation only consider the effect of economic allocation of GGFS on the LCA results.

\section{b. Allocation of AF}

According to the ecoinvent dataset on the clinker production, $\mathrm{CO}_{2}$ emissions caused by burning alternative fuels are included in LCI as fossil and non-fossil $\mathrm{CO}_{2}$ emissions. GWP only includes fossil $\mathrm{CO}_{2}$-emissions. An alternative allocation rule suggested in some LCA studies don't consider any emissions caused by burning alternative fuels because they are regarded as part of the waste treatment processes in the former life cycle of these goods (see 2.2). We analyse this effect in scenario calculation by substracting $\mathrm{CO}_{2}$ emissions from non-biomass fuels (waste tires, waste oil, waste solvents etc.) using data from (Boesch and Hellweg, 2010).

\section{c. System Boundary Considering Carbon Uptake}

In the withdrawn prEN 16757 (DIN Deutsches Institut für Normung e.V., 2016) an allocation method for the carbon uptake is presented. There, several calculations are made to estimate the carbon uptake in total, during service life of concrete structures and th its usage stage and in its end-of-life phase. The formula for calculating the maximum carbon uptake is as follows:

$$
\begin{aligned}
\mathrm{CO}_{2}-\text { uptake } & \\
& =\left(\frac{\% \text { reactive } \mathrm{CaO}}{100}\right) \times \text { binder content } \\
& \times \frac{\text { molar weight of } \mathrm{CO}_{2}}{\text { molar weight of } \mathrm{CaO}}
\end{aligned}
$$

Where the amount of reactive $\mathrm{CaO}$ is about $65 \%$, the molar weight of $\mathrm{CO}_{2}$ is $44 \mathrm{~g} / \mathrm{mol}$ and for $\mathrm{CaO} 56 \mathrm{~g} / \mathrm{mol}$, respectively. If we apply the calculation to the mix designs

\begin{tabular}{|c|c|c|c|c|c|c|c|c|c|c|}
\hline & 1 & 2 & 3 & 4 & 5 & 6 & 7 & 8 & 9 & 10 \\
\hline $\begin{array}{r}\text { max. carbon uptake } \\
{\left[\mathrm{kg} \mathrm{CO} \mathrm{CO}_{2}\right]}\end{array}$ & 136 & 146 & 155 & 170 & 136 & 114 & 93 & 50 & 29 & 7 \\
\hline $\begin{array}{r}30 \% \text { carbon uptake } \\
{[\mathrm{kg} \mathrm{CO} 2]}\end{array}$ & 41 & 44 & 47 & 51 & 41 & 34 & 28 & 15 & 9 & 2 \\
\hline
\end{tabular}
listed here, the following maximum carbon uptake are as follows:

Table 3: maximum carbon uptake of the considered concrete mix designs

It reveals the potential of uptake of carbon dioxide from the air, to lower environmental impact of the concrete product system regarding $\mathrm{CO}_{2}$. However, it must be noted that the carbonation of concrete depends on several conditions such as density of the 
concrete, exposure to the weather, service life and so on. Therefore, a maximum carbonation is quite unrealistic. Assuming, that around $30 \%$ of the carbonation can be reached during service life and end-of-life phase (InformationsZentrum Beton GmbH, 2018), Table 3 also shows the uptake of $30 \%$ of the calculated maximum uptake.

It can be seen, that a maximum carbonation would lead to a significant uptake of carbon dioxide from the air, which in turn would lead to a significant lower environmental impact regarding $\mathrm{CO}_{2}$. However, it must be noted that the carbonation of concrete depends on several conditions such as density of the concrete, exposure to the weather, service life and so on. Therefore, a maximum carbonation is quite unrealistic. Nevertheless, the carbon uptake is a process that can reduce the environmental impact of concrete, which can seen in the results with $30 \%$ uptake. Up to $51 \mathrm{~kg} \mathrm{CO} 2$ can be bound back in the mix 4 with $350 \mathrm{~kg}$ cement. Due to its chemical composition, blast furnace slag is not able to capture $\mathrm{CO}_{2}$ like ordinary portlant cement, which can also be seen in Table 3 .

\section{RESULTS}

In Figure 3, the results of the variation of technical parameters without allocation are shown. The details are described in the following subsections.

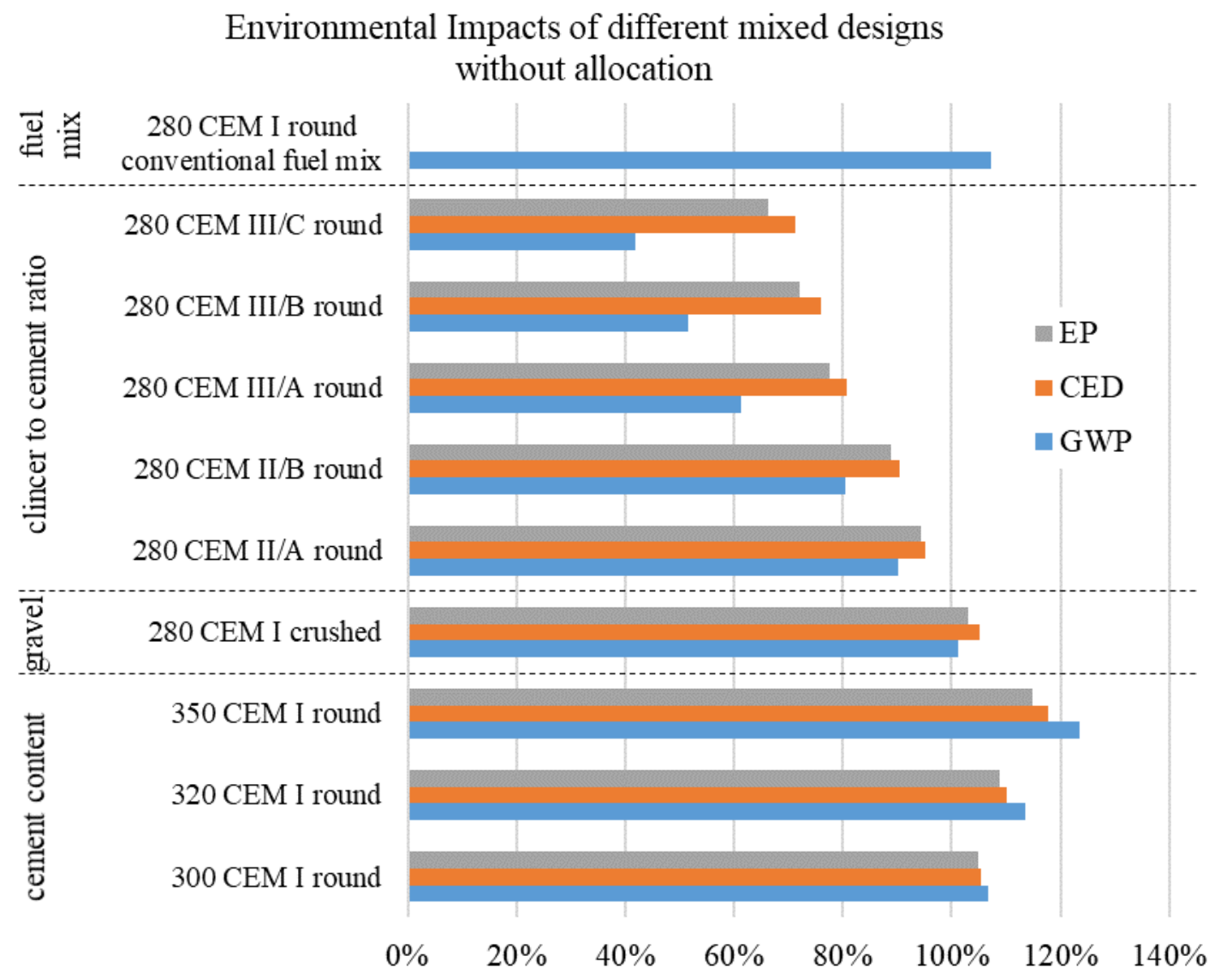


Figure 3: Environmental impacts (without allocation) of concrete mix designs defined in Figure 2 in relation to the reference concrete $(=100 \%)$. EP: Ecopoints as defined by Ecological scarcity 2013, CED: Cumulative energy demand, GWP: Global warming potential.

\section{a) Global Warming Potential}

GWP of the reference concrete adds up to $230 \mathrm{~kg} \mathrm{CO}_{2}$-eq. in the entire product system, but most of it is caused by clinker production $\left(217 \mathrm{~kg} \mathrm{CO}_{2}\right.$-eq. $)$. As the cement content is increased (mix designs numbers $2-3$ in Figure 2) the overall GWP grows accordingly. The influence of using crushed aggregates (number 5) is small. Using round aggregate results in $9.7 \mathrm{~kg} \mathrm{CO}_{2}$-eq.in the reference concrete, while $12.6 \mathrm{~kg} \mathrm{CO}_{2}$ eq. are emitted in the crushed aggregate concrete. The highest decreasing of the GWP is recognizable by substituting the clinker with grounded blast furnace slag (number 6 - 10). With a blast furnace slag content of $90 \%, \mathrm{CO}_{2}$ emissions can be reduced to 97 $\mathrm{kg} \mathrm{CO}$-eq. which corresponds with a reduction of $60 \%$.

\section{b) Cumulative Energy Demand}

As shown in Figure 3, the cumulative energy demand is comparable with the results of the GWP. While the reference concrete has an energy demand of 1'040 MJ of which $66 \%$ are non-renewable fossil sources and $23 \%$ non-renewable nuclear sources, the energy demand increases with higher cement content to 1'222 MJ (cement-content 350 $\mathrm{kg} / \mathrm{m}^{3}$ ). Compared to the reference concrete, the crushing of aggregates results in an increase of energy demand of $5 \%$ to an overall consumption of $1091 \mathrm{MJ}$. Again, high saving in the energy demand can be seen by substituting the Clinker with blast furnace slag. Less energy is needed with higher slag content. Comparing the reference concrete with the concrete with the highest slag content, the energy demand is reduced by 300 MJ or by $29 \%$.

\section{c) Ecological Scarcity}

The impacts according the method of ecological scarcity is also shown in Figure 3. It can be seen, that the impacts of the reference concrete is about 212000 eco-points. $50 \%$ (106 400 ecopoints) results by the global warming impact, while $29 \%$ (60 700 points) are caused by the depletion of mineral resources and $12 \%$ (25850 points) by main air pollutants. The remaining $9 \%$ are caused by several impacts like radioactive waste, heavy metals or energy in general. Furthermore, it can be seen that in accordance to the GWP and CED a higher cement content leads to a higher ecological scarcity mainly due to the higher global warming impact. In addition, the crushing of the aggregate results in an overall increase of the single categories, which leads also to a higher ecological scarcity. This is negligible as we see only increase of about 6000 ecopoints (3\%). Comparable with the results of the GWP and CED, the concrete mix design with increasing blast furnace slag contents, the ecological scarcity decreases significantly from 200000 eco-points and a slag content of $15 \%$ to 140000 eco-points $(-30 \%)$ with a slag content of $90 \%$. 


\section{Influence of Allocation}

In Table 4, the results of the variation of technical parameters are shown. The details ae described in the following subsections.

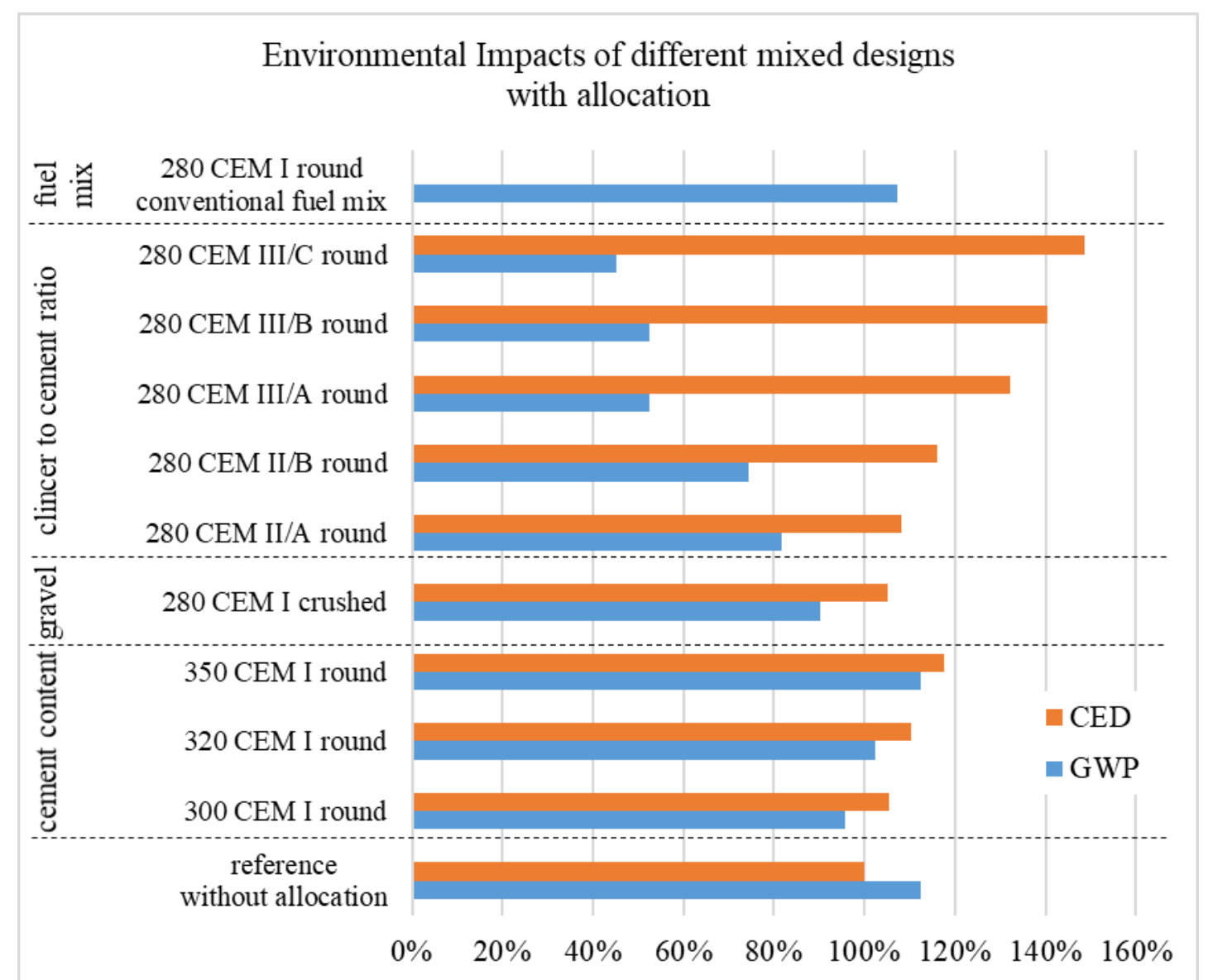

Figure 4: Environmental impacts (with allocation) of concrete mix designs defined in figure 2 in relation to the reference concrete $(=100 \%)$. CED: Cumulative energy demand, GWP: Global warming potential.

\section{a) Allocation of Ground Granulated Blast Furnace Slag}

According the allocation rules described in 4.2 , in relation to the concrete mix design considered in this study, the allocation of blast furnace slag would lead to the following higher environmental impacts (see Figure 4).

Table 4: Environmental impact of GBFS with allocation

\begin{tabular}{|rrr|r|r|r|r|}
\hline mix & $\mathbf{6}$ & \multicolumn{1}{c|}{$\mathbf{7}$} & \multicolumn{1}{c|}{$\mathbf{8}$} & \multicolumn{1}{c|}{$\mathbf{9}$} & \multicolumn{1}{c|}{$\mathbf{1 0}$} \\
\hline & blast furnace slag [kg] & 42 & 84 & 168 & 210 & 252 \\
\hline blast furnace slag eq. & 38 & 76 & 151 & 189 & 227 \\
\hline \multirow{2}{*}{ mass allocation } & GWP [kg CO2-eq.] & 53 & 105 & 210 & 263 & 315 \\
\cline { 2 - 7 } & CED [MJ] & 839 & 1678 & 3357 & 4196 & 5035 \\
\hline
\end{tabular}




\begin{tabular}{|rrr|r|r|r|r|}
\hline $\begin{array}{r}\text { economic } \\
\text { allocation }\end{array}$ & GWP [kg CO2-eq.] & 6 & 11 & 23 & 28 & 34 \\
\hline
\end{tabular}

According to Table 4, the environmental impact of blast furnace slag would increase significantly. Depending on the allocation method, the GWP of blast furnace slag would increase in the concrete mix number 6 (15 kg blast furnace slag) $9 \%$ (mass allocation) or just $1 \%$ (economic allocation). In mix number 10 , with $90 \%$ or $252 \mathrm{~kg}$ blast furnace slag, the GWP would increase $117 \%$ (mass allocation) or just $12 \%$. The CED would increase accordingly. In the mix 6 , the CED would increase by $30 \%$ (mass allocation) or $5 \%$ (economic allocation), respectively. In the extreme case (number 10) the CED would increase by $242 \%$ if allocated based on mass. If the allocation is done based on economic aspects it would be around $39 \%$.

\section{b) Alternative Fuels}

In the present calculations an average fuel mix for Switzerland has been defined. This fuel mix in relation to the heat value consists of about $50 \%$ conventional fossil fuels, $36.7 \%$ alternative fuels and $13.4 \%$ biomass fuels (see Figure 2). With data from (Boesch and Hellweg, 2010) on $\mathrm{CO}_{2}$ emissions per $\mathrm{GJ} / \mathrm{kg}$ clinker, the overall $\mathrm{CO}_{2}$ emmissions per $\mathrm{kg}$ clinker are calculated to $0.260 \mathrm{~kg} \mathrm{CO}_{2}$. For the reference concrete, and a clinker content of $266 \mathrm{~kg}$, the $\mathrm{CO}_{2}$ emmission would amount to roughly $69 \mathrm{~kg}$ $\mathrm{CO}_{2}$ per $\mathrm{m}^{3}$ concrete. According the ecoinvent dataset on the clinker production, the $\mathrm{CO}_{2}$ emmissions of the alternative fuels are included in the environmental flows for fossil and non-fossil $\mathrm{CO}_{2}$ emmissions. Biomass-fuels are not included. By varying the content of conventional and alternative fuels, the $\mathrm{CO}_{2}$ emmissions can be affected accordingly. As example, a alternative mixes was defined to validate the possible variations in the $\mathrm{CO}_{2}$ emmissions. The "conventional mix" represents a fuel mix only with concentional fuels, $45 \%$ coal and petrol coke, respectively, and $10 \%$ lignite. This mix emmits $0.324 \mathrm{~kg} \mathrm{CO}_{2}$ per kg Clinker (+24\%), which results in $86 \mathrm{~kg} \mathrm{CO}_{2}$ per m concrete of the reference mix. By allocating the alternative fuels of the reference mix, the $\mathrm{CO}_{2}$-emmission would decrease significantly by $37 \%$ to $0.163 \mathrm{~kg} \mathrm{CO}$ per $\mathrm{kg}$ Clinker which is about half of the emissions caused by the "conventional mix" with only fossil fuels.

\section{DISCUSSION}

In this study, we discussed, why results of LCAs for concrete can differ so much. From a technological point of view, differences can be accounted to variations of cement content, clinker to cement ratio or share of alternative fuels in the fuel mix in cement production. Such variations are caused by regional availability of secondary resources, differences in construction standards and specific aspects in the value chain of concrete like the devision of labor and responsibility between cement and concrete producers in developing concrete mix designs. Differences can also be accounted to alternative methodological choices in LCA. The choice of the system boundary can influence the results of the LCA significantly. Important processes like the carbon uptake during service life and recycling of concrete are neglected when choosing the cradle-to-gate approach. Thus, CO2 emissions revealed in "cradle to gate" LCA studies appear to be 
higher than they really are. Allocation rules for SCMs (e.g. ground granulated blast furnace slag GBFS) or alternative fuels have a relevant effect on LCA results for GWP. In most LCA studies, the GBFS come "burden-free" into the concrete product system, as by-product of the steel-industry. If allocated by mass or market prices, environmental impacts attributed GBFS increase. The same applies for alternative fuels. If CO2-emissions caused by burning alternative fuels are attributed to the former life cycles of goods generating these wastes, the GWP of the concrete product systems decreases.

As practical guidelines for the interpretation of LCA results of concrete building materials we suggest focusing on cement content, clinker to cement ratio and share of alternative fuels in the fuel mix in cement production. Most variations between the results of LCA studies can be explained by differences of these parameter values. In recent LCA studies, alternative methodological choices have a significant effect on GWP. This can be explained by the fact that the cement industry is in the focus of political debates on global warming and exposed to incentives/regulations to reduce $\mathrm{CO} 2$ emissions. It is understandable that EPDs sponsored by the cement industry try to highlight possibilities to reduce $\mathrm{CO} 2$ emissions of GWP by using alternative fuels and by carbon uptake during the life cycle of concrete structures. Yet, this is well within the methodological framework of LCA.

For advancing LCA calculating techniques for concret, we suggest harmonizing allocation rules for SCMs and alternative fuels. Economic allocation for SCMs seems reasonable because they should be considered as by-product of steel production. And, there are good reasons to attribute $\mathrm{CO} 2$-emission caused by burning wastes to the former life cycle of waste producing goods. Both allocation rules promote the use of secondary resources in the concrete product system. Yet, from our point of view carbon-uptake during service life and recycling of concrete structures seems an issue needing further research before being included in LCA studies. If the maximum carbon-uptake was considered, GWP of concrete would be reduced significantly and it would be almost no advantage to further reduce cement content and the clinker to cements ratios. One could seriously question, whether such information would encourage progress in sustainable construction.

\section{ACKNOWLEDGMENT}

Supported by the Swiss National Science Foundation (SNSF) within the framework of the National Research Programme "Sustainable Economy: resource-friendly, futureoriented, innovative" (NRP 73).

\section{REFERENCE LIST}

Abd Rashid, A.F. and Yusoff, S. (2015) 'A review of life cycle assessment method for building industry', Renewable and Sustainable Energy Reviews, 45, pp. 244-248. doi: 10.1016/j.rser.2015.01.043 
Aranda Usón, A. et al. (2013) 'Uses of alternative fuels and raw materials in the cement industry as sustainable waste management options', Renewable and Sustainable Energy Reviews, 23, pp. 242-260. doi: 10.1016/j.rser.2013.02.024

Augiseau, V. and Barles, S. (2017) 'Studying construction materials flows and stock: A review', Resources, Conservation and Recycling, 123, pp. 153-164. doi: 10.1016/j.resconrec.2016.09.002

Boesch, M.E. and Hellweg, S. (2010) 'Identifying improvement potentials in cement production with life cycle assessment', Environmental Science \& Technology, 44(23), pp. 9143-9149. doi: 10.1021/es100771k

Butera, S., Christensen, T.H. and Astrup, T.F. (2015) 'Life cycle assessment of construction and demolition waste management', Waste Management (New York, N.Y.), 44, pp. 196-205. doi: 10.1016/j.wasman.2015.07.011

Buyle, M., Braet, J. and Audenaert, A. (2013) 'Life cycle assessment in the construction sector: A review', Renewable and Sustainable Energy Reviews, 26, pp. 379-388. doi: 10.1016/j.rser.2013.05.001

CEMBUREAU The European Cement Association (2013) The role of cement in the 2050 low carbon economy. Brussels. Available at: https:// lowcarboneconomy.cembureau.eu/downloads/ (Accessed: 29 November 2018).

Cementos Argos Panamá (2014) Environmental Product Declaration (EPD) for Concrete. Silver Spring: National Ready Miced Concrete Association.

CemSuisse (2016) Durchschnittszement Schweiz, (2015). Bern: cemsuisse.

CemSuisse (2018) Kennzahlen 2018. Bern. Available at: http://www.cemsuisse.ch/ cemsuisse/ueberuns/publikationen/jahresberichte/index.html?lang=de (Accessed: 17 November 2018).

Chen, C. et al. (2010) 'LCA allocation procedure used as an incitative method for waste recycling: An application to mineral additions in concrete', Resources, Conservation and Recycling, 54(12), pp. 1231-1240. doi: 10.1016/j.resconrec.2010.04.001

DIN Deutsches Institut für Normung e.V. (2016) Nachhaltigkeit von Bauwerken Umweltproduktdeklarationen - Produktkategorieregeln für Beton und Betonelemente. Berlin: Beuth Verlag GmbH.

Dossche, C., Boel, V. and Corte, W. de (2017) 'Use of Life Cycle Assessments in the Construction Sector: Critical Review', Procedia Engineering, 171, pp. 302-311. doi: 10.1016/j.proeng.2017.01.338

Ehrenberg, A. (2018) 'Methoden zur Bewertung des ökologischen Einflusses von Eisenhüttenschlacken', Strasse und Autobahn (10), pp. 836-843.

Finnveden, G. et al. (2009) 'Recent developments in Life Cycle Assessment', Journal of Environmental Management, 91(1), pp. 1-21. doi: 10.1016/j.jenvman.2009.06.018 
Frischknecht, R., Büsser, S. and Knöpfel, S. (2013) Ökofaktoren Schweiz 2013 gemäss der Methode der ökologischen Knappheit.: Methodische Grundlagen und Anwendung auf die Schweiz. Bern (Umwelt-Wissen 1330).

Habert, G. (2013) 'A method for allocation according to the economic behaviour in the EU-ETS for by-products used in cement industry', The International Journal of Life Cycle Assessment, 18(1), pp. 113-126. doi: 10.1007/s11367-012-0464-1

Habert, G. et al. (2018) A sustainable future for the European Cement and Concrete Industry: Technology assessment for full decarbonisation of the industry by 2050.

InformationsZentrum Beton GmbH (2018) Beton der Druckfestigkeitsklasse C 25/30. Berlin: Institut Bauen und Umwelt e.V. (IBU).

International Energie Agency (IEA) and The Cement Sustainability Initiative (CSI) (2018) Technology Roadmap: Low-Carbon Transition in the Cement Industry. Available at: https://www.iea.org/publications/freepublications/publication/ TechnologyRoadmapLowCarbonTransitionintheCementIndustry.pdf (Accessed: 11 October 2018).

ISO/TC 59/SC 17 (2017) Sustainability in buildings and civil engineering works.

Leemann, A. and Hunkeler, F. (2016) Carbonation of concrete: assessing the CO2 uptake: Report cemsuisse project 201602.

Leemann, A., Hunkeler, F. and Widmer, H. (2018) 'Assessing the CO2-Binding of concrete during its service life', SynerCrete'18: Interdisciplinary Approaches for Cement-based Materials and Structural Concrete: Synergizing Expertise and Bridging Scales of Space and Time., pp. 653-658.

Liew, K.M., Sojobi, A.O. and Zhang, L.W. (2017) 'Green concrete: Prospects and challenges', Construction and Building Materials, 156, pp. 1063-1095. doi: 10.1016/j.conbuildmat.2017.09.008

Müller, H.S., Haist, M. and Vogel, M. (2014) 'Assessment of the sustainability potential of concrete and concrete structures considering their environmental impact, performance and lifetime', Construction and Building Materials, 67, pp. 321-337. doi: 10.1016/j.conbuildmat.2014.01.039

Passer, A. et al. (2015) 'Environmental product declarations entering the building sector: critical reflections based on 5 to 10 years experience in different European countries', The International Journal of Life Cycle Assessment, 20(9), pp. 1199-1212. doi: 10.1007/s11367-015-0926-3

Petek Gursel, A. et al. (2014) 'Life-cycle inventory analysis of concrete production: A critical review', Cement and Concrete Composites, 51, pp.38-48. doi: 10.1016/j.cemconcomp.2014.03.005

Preston, F. and Lehne, J. (2018) Making Concrete Change: Innovation in Low-carbon Cement and Concrete. Available at: https://reader.chathamhouse.org/makingconcrete-change-innovation-low-carbon-cement-and-concrete (Accessed: 11 October 2018). 
Rebitzer, G. et al. (2004) 'Life cycle assessment part 1: framework, goal and scope definition, inventory analysis, and applications', Environment International, 30(5), pp. 701-720. doi: 10.1016/j.envint.2003.11.005

Salas, D.A. et al. (2016) 'Environmental impacts, life cycle assessment and potential improvement measures for cement production: a literature review', Journal of Cleaner Production, 113, pp. 114-122. doi: 10.1016/j.jclepro.2015.11.078

Schneider, M. et al. (2011) 'Sustainable cement production-present and future', Cement and Concrete Research, 41(7), pp. 642-650. doi: 10.1016/j.cemconres.2011.03.019

Schweizerische Normen-Vereinigung (2006a) Umweltmanagement - Ökobilanz Anforderungen und Anleitungen.

Schweizerische Normen-Vereinigung (2006b) Umweltmanagement - Ökobilanz Grundsätze und Rahmenbedingungen.

Schweizerischer Ingenieur- und Architektenverein SIA (2011) Zement - Teil 1: Zusammensetzung, Anforderungen und Konformitätskriterien von Normalzement.

Schweizerischer Ingenieur- und Architektenverein SIA (2014) Nachhaltigkeit von Bauwerken - Umweltproduktdeklarationen - Grundregeln für die Produktkategorie Bauprodukte. Zürich: Schweizerischer Ingenieur- und Architektenverein SIA.

Schweizerischer Ingenieur- und Architektenverein SIA (2016) Concrete Specification, performance, production and conformity.

Suhendro, B. (2014) 'Toward Green Concrete for Better Sustainable Environment', Procedia Engineering, 95, pp. 305-320. doi: 10.1016/j.proeng.2014.12.190

Supino, S. et al. (2016) 'Sustainability in the EU cement industry: the Italian and German experiences', Journal of Cleaner Production, 112, pp. 430-442. doi: 10.1016/j.jclepro.2015.09.022

Tait, M.W. and Cheung, W.M. (2016) 'A comparative cradle-to-gate life cycle assessment of three concrete mix designs', The International Journal of Life Cycle Assessment, 21(6), pp. 847-860. doi: 10.1007/s11367-016-1045-5

The National Ready Mixed Concrete Assosiaction (2016) NRMCA Member IndustryWide EPD For Ready Mixed Concrete. Ann Arbor: NSF International.

van den Heede, P. and Belie, N. de (2012) 'Environmental impact and life cycle assessment (LCA) of traditional and 'green' concretes: Literature review and theoretical calculations', Cement and Concrete Composites, 34(4), pp. 431-442. doi: 10.1016/j.cemconcomp.2012.01.004 